\title{
Increased rate of lipid peroxidation and protein carbonylation in experimental diabetic pregnancy
}

\author{
J.Cederberg ${ }^{1}$, S. Basu ${ }^{2}$, U.J. Eriksson ${ }^{1}$ \\ ${ }^{1}$ Department of Medical Cell Biology, Uppsala University, Uppsala, Sweden \\ ${ }^{2}$ Section of Geriatrics/Clinical Nutrtion Research, Uppsala University, Uppsala, Sweden
}

\begin{abstract}
Aims/hypothesis. Maternal Type I (insulin-dependent) diabetes mellitus is associated with an increased risk for fetal malformations and spontaneous abortions. Although the pathogenic mechanism is not fully understood, reactive oxygen species have been shown to contribute to the pathogenesis in experimental studies. By measuring 8-iso-PGF ${ }_{2 \alpha}$ and protein carbonyls, radical oxygen damage to lipids and proteins can be estimated. The aim of this study was to investigate the status of lipid peroxidation and protein carbonylation in mothers and fetuses in experimental diabetic pregnancy.

Methods. Non-pregnant and pregnant rats with and without streptozotocin-induced diabetes were studied after 4 weeks of diabetes or at gestational day 19, respectively. Gross morphology of the offspring was studied and $24 \mathrm{~h}$ urine, plasma, amniotic fluid, maternal and fetal livers were collected. Concentrations of 8 -iso-PGF $2 \alpha, 15$-keto-DH-PGF ${ }_{2 \alpha}$ and other oxidative stress variables were measured.

Results. Malformation and resorption rates were in-
\end{abstract}

creased in diabetic litters, whereas fetal weights were decreased in the control rats. There were no statistically significant differences in maternal plasma concentrations of 8 -iso- $\mathrm{PGF}_{2 \alpha}$, but plasma protein carbonyl content was increased in the diabetic groups. Pregnancy increased $24 \mathrm{~h}$ urinary excretion of 8 -iso-PGF ${ }_{2 \alpha}$ in diabetic rats but not in the control rats. There was no difference in the amniotic fluid concentration of 8 -iso- $\mathrm{PGF}_{2 \alpha}$ between the normal and the diabetic group. However, in the diabetic group there was a correlation between the uterine horn concentration of 8-iso-PGF $2 \alpha$ and the percentage of resorptions.

Conclusions/interpretation. In diabetic pregnancy, both diabetes and pregnancy are promoting oxygen radical damage. Fetal oxidative stress markers do not clearly reflect fetal morphology. [Diabetologia (2001) 44: 766-774]

Keywords Diabetes, rat, streptozotocin, pregnancy, free oxygen radicals, isoprostanes, protein carbonylation, malformations, amniotic fluid.
Received: 11 December 2000 and in revised form: 18 January 2001

Corresponding author: J. Cederberg, Uppsala University, Department of Medical Cell Biology, Box 571, BMC, 75123 Uppsala

Abbreviations: 8-iso- $\mathrm{PGF}_{2 \alpha}$, 8-iso-prostaglandin $\mathrm{F}_{2 \alpha} ; 15-\mathrm{K}$ DH-PGF ${ }_{2 \alpha}$, 15-keto-13,14-dihydro-prostaglandin $\mathrm{F}_{2 \alpha}$; D, nonpregnant diabetic female rats; DP, pregnant diabetic female rats; $\mathrm{N}$, non-pregnant normal female rats; NP, normal pregnant female rats; ROS, reactive oxygen species; STZ, Streptozotocin; TBA, thiobarbituric acid; TBARS, thiobarbituric acid reactive substances.
Despite better regimens for treatment of Type I (insulin-dependent) diabetes mellitus, maternal diabetes is still associated with an increased risk for malformed and spontaneously aborted offspring [1, 2]. The malformations are induced before the seventh post-conceptional week in humans [3] and during organogenesis in rats [4]. High maternal $\mathrm{HbA}_{1 \mathrm{c}}$ concentrations during early pregnancy are associated with an increased risk for malformations [5-7] and the risk seems to increase even with a slight worsening of metabolic control [1]. Throughout the last ten years, increasing evidence has indicated a role for re- 
active oxygen species (ROS) in the development of diabetes-induced malformations in rodent models $[8$, 9]. Antioxidants have been shown to protect the offspring of diabetic rats against malformations [10-15].

In 1990 biosynthesis and the release of isoprostanes in vivo were described [16]. These isomers of prostaglandins are formed through a direct non-enzymatic reaction of arachidonic acid with a free radical. The isoprostanes have gained increasing interest as reliable biomarkers for lipid peroxidation, that is, ROS damage to lipids. One of the more abundant isoprostanes formed in vivo is 8-iso- $\mathrm{PGF}_{2 \alpha}$ [17], which is also the most extensively studied isoprostane. Vasoconstrictor effects of 8 -iso-PGF ${ }_{2 \alpha}$ have been observed at low concentrations, for example, in the glomeruli [18] and retina of rats [19]. In addition, an increased concentration of 8 -iso-PGF $2 \alpha$ in both maternal and fetal plasma of STZ-diabetic rats has been reported recently [20]. Carbonyl groups can be introduced into the side-chains of amino-acid residues by a reaction between oxygen radicals and the proteins [21]. Protein carbonyl content can therefore be used to measure oxygen radical damage of proteins. Carbonylated proteins have been found in the intima of arteries of diabetic patients with poor diabetic control [22] and to correlate positively with $\mathrm{HbA}_{1 \mathrm{c}}$ in patients with Type II (non-insulin-dependent) diabetes mellitus [23]. These markers yield measures of ROSdamage to lipids and proteins, respectively.

Estimation of a major metabolite of $\mathrm{PGF}_{2 \alpha}, 15-$ keto-13,14-dihydro-PGF ${ }_{2 \alpha}$ (15-K-DH-PGF $\left.2 \alpha\right)$ in body fluids provides an indirect measure of cyclooxygenase activity. $\mathrm{PGF}_{2 \alpha}$ is a potent bioactive compound [24] and has been shown to be increased in the peripheral circulation during luteolysis, parturition [25] and inflammation [26, 27].

Considering the possible role for ROS in the pathogenesis of diabetic embryopathy, the isoprostanes can serve both as biomarkers for oxidative stress and as mediators of ROS teratogenicity in diabetic pregnancy. The concentrations of 8 -iso-PGF ${ }_{2 \alpha}$ have been found to be higher in day 11 embryos of diabetic rats compared with embryos of normal rats; also in-vitro culture in high glucose increased the concentrations of 8-iso- $\mathrm{PGF}_{2 \alpha}$ in embryonic tissue [28].

We wanted to investigate signs of ROS-damage to lipids and proteins in both mothers and fetuses in experimental diabetic pregnancy and thereby attempt to find late-gestation markers of oxidative stress that correlate with morphological outcome. The aims of our study were to evaluate the effect of maternal diabetes on the concentration of 8 -iso- $\mathrm{PGF}_{2 \alpha}$ and the rate of protein carbonylation, as well as to search for a possible association between estimated oxidative damage and outcome of pregnancy.

\section{Materials and methods}

Animals. Sixty-four outbred female Sprague Dawley rats with a weight of about $250 \mathrm{~g}$ were housed at the Laboratory Animal Resources of the Biomedical Centre in Uppsala. The animals were subjected to a $12 \mathrm{~h}$ dark/12 h light cycle. During the entire experiment the rats had free access to food (the commercial pellet R36, Lactamin, Stockholm, Sweden; in powdered form in the metabolic cages) and water. Rats were given an intravenous injection of $40 \mathrm{mg} / \mathrm{kg}$ streptozotocin (STZ, a gift from Pharmacia and Upjohn, Kalamazoo, Mich., USA) to induce diabetes. Serum glucose was measured (Glucose Analyzer 2, Beckman Instruments, Fullerton, Calif., USA) in tail vein blood one week after the STZ injection. Diabetes was defined as a serum glucose concentration exceeding $20 \mathrm{mmol} / \mathrm{l}$. Nondiabetic and diabetic rats were mated overnight with normal male rats of the same strain; day 0 of pregnancy was defined as the day sperm were observed in vaginal smear. During the last 24 hours of the experiment, i.e. from gestational day 18 , the rats were housed in metabolic cages to collect $24 \mathrm{~h}$ urine samples. The pregnant and non-pregnant rats were killed by exsanguination on gestational day 19 and four weeks after the STZ injection, respectively. Plasma samples were collected from the abdominal aorta of each rat under ether anesthesia. All animal experiments were carried out with the approval from the Animal Ethics Committee of the Medical Faculty of Uppsala University, and the "Principles of laboratory animal care" (NIH publication no. 85-23, revised 1985) were followed.

Plasma, urine, liver and amniotic fluid samples were collected and snap frozen in liquid nitrogen and thereafter stored at $-135^{\circ} \mathrm{C}$ until analysis. In a first series amniotic fluid samples were pooled from all the individual amniotic sacs of each uterine horn. In a second series consisting of 3 normal and 9 diabetic pregnancies, amniotic fluid was collected from individual amniotic sacs in order to compare the concentration of 8-iso$\mathrm{PGF}_{2 \alpha}$ and 15-K-DH-PGF ${ }_{2 \alpha}$ in amniotic fluid of normal and malformed fetuses. Maternal livers for TBARS measurements were homogenized in distilled water to a concentration of 0.2 $\mathrm{g} / \mathrm{ml}$ in a glass homogenizer on ice. All offspring were inspected for gross malformations and weighed. All dead offspring, regardless of age, were classified as resorptions. The number of implantations was the sum of the number of living fetuses plus the number of resorptions.

Measurement of 8-iso- $P G F_{2 \alpha}$ and $15-K-D H-P G F_{2 \alpha}$. Two newly developed RIA methods $[29,30]$ were used to measure 8-iso$\mathrm{PGF}_{2 \alpha}$ and 15-K-DH-PGF $2 \alpha$, respectively. Antibodies have been raised by the immunization of rabbits with either substance, coupled to bovine serum albumin. The cross-reactivity of the 8-iso-PGF ${ }_{2 \alpha}$ antibody with 8-iso-15-keto-13, 14-dihydro-PGF ${ }_{2 \alpha}, 8$-iso-PGF $2 \beta, \mathrm{PGF}_{2 \alpha}$, 15-keto-PGF $\mathrm{PG}_{2 \alpha}, 15$-keto-13, 14-dihydro-PGF ${ }_{2 \alpha}, \mathrm{TXB}_{2}, 11 \beta$ - $\mathrm{PGF}_{2 \alpha}, 9 \beta-\mathrm{PGF}_{2 \alpha}$ and 8 -iso$\mathrm{PGF}_{3 \alpha}$ was $1.7,9.8,1.1,0.01,0.01,0.1,0.03,1.8$ and $0.6 \%$, respectively. The cross-reactivity of the 15-K-DH-PGF $2 \alpha$ antibody with $\mathrm{PGF}_{2 \alpha}, 15-$ keto-PGF $\mathrm{PG}_{2 \alpha}, \mathrm{PGE}_{2}, 15$-keto-13,14 dihydro-PGE $2, \quad 8$-iso-15-keto-13,14-dihydro-PGF $2 \alpha, \quad 11 \beta$-PGF $2 \alpha$, $9 \beta-\mathrm{PGF}_{2 \alpha}, \mathrm{TXB}_{2}$ and 8 -iso-PGF $3 \alpha$ was $0.02,0.43,<0.001,0.5$, $1.7,<0.001,<0.001,<0.001$ and $0.01 \%$, respectively. The lower limit of detection was $23 \mathrm{pmol} / \mathrm{l}$ for the 8-iso-PGF ${ }_{2 \alpha}$-RIA and $45 \mathrm{pmol} / \mathrm{l}$ for the $15-\mathrm{keto}-\mathrm{DH}-\mathrm{PGF}_{2 \alpha}$-RIA. Unextracted plasma $(500 \mu \mathrm{l})$, urine $(50 \mu \mathrm{l})$ and amniotic fluid $(200 \mu \mathrm{l})$ were used in the assays.

Measurement of $\alpha$-tocopherol. Plasma $\alpha$-tocopherol was measured using HPLC with fluorescence detection as in [31]. In brief, $500 \mu$ l plasma was extracted with an equal volume of eth- 
anol (containing $0.05 \mathrm{~g} / \mathrm{l}$ butylated hydroxytoluene) and $2 \mathrm{ml}$ hexane. A volume of $20 \mu \mathrm{l}$ of the supernatant was subsequently injected into a LiChrospher $100 \mathrm{NH} 2250 \times 4$ column. The fluorescence of the effluent was measured at $327 \mathrm{~nm}$ using an excitation wavelength of $295 \mathrm{~nm}$. Standard samples were prepared from $\alpha$-tocopherol (E. Merck, Darmstadt, Germany).

Measurement of cholesterol, triglycerides and creatinine. The cholesterol concentration in plasma was analysed using the kit IL Test Cholesterol (Instrumentation Laboratory, Lexington, Mass., USA) and the manufacturer's instructions were followed. The concentration of triglycerides was measured using the kit IL Test Triglyceride (Instrumentation Lab.), yielding a dye that was estimated spectrophotometrically at $550 \mathrm{~nm}$. Creatinine was measured using a commercial IL Test Creatinine (Instrumentation Lab.). A Monarch 2000 centrifugal analyser (Monarch Instrument, Amherst, N.H., USA) was used for the cholesterol, triglyceride and creatinine measurements.

Measurement of ascorbate. Ascorbic acid was analysed as previously described [32]. Standard samples were prepared from ascorbic acid dissolved in distilled water (E. Merck). An aliquot of $200 \mu \mathrm{l}$ of plasma was precipitated on ice with $800 \mu \mathrm{l}$ trichloroacetic acid (E. Merck) for 5 min and then centrifuged at $4000 \mathrm{rpm}$ (12000 g) for $5 \mathrm{~min}$. The supernatants were subsequently diluted with distilled water to $1 \mathrm{ml}$ and $200 \mu \mathrm{l}$ of FolinCiocalteaus solution (E. Merck) was added to the samples that were immediately shaken. After $10 \mathrm{~min}$ the absorbance at $760 \mathrm{~nm}$ was measured using a Beckman DU-65 spectrophotometer (Beckman Instruments, Fullerton, Calif., USA) and compared with a standard curve.

Measurement of TBARS. The TBARS were measured fluorometrically after boiling samples with TBA. A volume of $200 \mu \mathrm{l}$ of plasma or liver homogenate was heated to $98^{\circ} \mathrm{C}$ for $60 \mathrm{~min}$ together with $250 \mu \mathrm{l} 42 \mathrm{mmol} / \mathrm{l}$ 2-thiobarbituric acid (Merck) and $750 \mu \mathrm{l} 0.19 \mathrm{mmol} / 1 \mathrm{H}_{3} \mathrm{PO}_{4}$. Standard samples were prepared from malondialdehyd-bis-(diethylacetal) (Merck-Schuchart, Schuchart, Germany). The samples were precipitated with a mixture of methanol and $1 \mathrm{~mol} / \mathrm{l} \mathrm{NaOH}$ (91:9) and centrifuged at $4000 \mathrm{rpm}(12000 \mathrm{~g})$ for $5 \mathrm{~min}$. Fluorescence was then measured in the supernatant using a Perkin-Elmer LS 5B luminescence spectrophotometer (Perkin-Elmer/Cetus, Norwalk, Conn., USA), the excitation wavelength was $532 \mathrm{~nm}$ and emission wavelength was 553 nm.

Measurement of protein carbonyls. Protein carbonyls were measured using a commercial ELISA kit (Zentech PC Test, Zenith Technology, Dunedin, New Zealand) following the manufacturer's instructions. In brief, $5 \mu$ plasma was incubated for 45 min with a 2,4-dinitrophenylhydrazine solution yielding 2,4-dinitrophenylhydrazone groups on protein carbonyls. The carbonylated proteins were then bound to a 96-well plate and antibodies towards hydrazone groups were used in the ELISA. Serum albumin was used as standard with five different concentrations of hypochlorous acid-oxidized protein. After the reactions, the absorbance was measured at $490 \mathrm{~nm}$ in a spectrophotometer.

Statistics. Analysis of variance (ANOVA) with the Bonferroni/ Dunn post-hoc test was used for test of difference between means. Test for significance of correlations was calculated using the Spearman rank method. Biochemical comparisons between groups in the amniotic fluid and in fetal livers were made using the Mann-Whitney U-test. Chi-square tests were done for the malformation data. Statistical calculations were
Table 1. Outcome of pregnancy

\begin{tabular}{lll}
\hline & Normal pregnancy & Diabetic pregnancy \\
\hline Fetal weight $(\mathrm{g})$ & $2.2 \pm 0.4$ & $1.7 \pm 0.04^{\mathrm{a}}$ \\
Implantations per litter & $13 \pm 1$ & $10 \pm 1^{\mathrm{a}}$ \\
$\%$ malformations & 0 & $23^{\mathrm{b}}$ \\
$\%$ resorptions & $2.6 \pm 1.9$ & $20 \pm 6^{\mathrm{a}}$
\end{tabular}

Values are given as means \pm SEM. ${ }^{\text {adenotes a difference from }}$

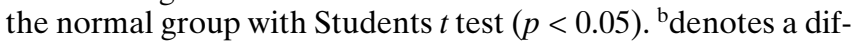
ference $(p<0.05)$ using a chi-square test. $n=8$ for normal pregnancy, $n=20$ for diabetic pregnancy

made using the software Statview for Macintosh computers. A $p$ value of less than 0.05 was considered to be statistically significant.

\section{Results}

Outcome of pregnancy. The animals in the experimental groups were normal non-pregnant $(\mathrm{N})$, normal pregnant (NP), diabetic non-pregnant (D) and diabetic pregnant (DP). The mean fetal weights were approximately $25 \%$ higher in fetuses from NP mothers than in fetuses from DP mothers (Table 1). The total number of implantations per litter was decreased in the DP group compared to the NP animals (Table 1). In the offspring of the pregnant rats no malformations in the NP group were observed whereas nearly one fourth of the fetuses in each uterine horn in the DP group showed gross malformations, mainly in the form of micrognathia (Table 1). A normal, day 19 fetus from a NP mother (Fig.1A) and a micrognatic fetus from a DP mother (Fig.1B) stained with Alizarin Red are shown. Also, the resorption rate was higher in the DP than in the NP group (Table 1).

At the end of the experiment, the rats in the $\mathrm{N}$ group weighed more than those in the $\mathrm{D}$ group (Table 2). Both pregnant groups weighed more than their non-pregnant counterparts and the NP rats weighed approximately $20 \%$ more than the DP rats (Table 2). In the DP group, the maternal weight at day 19 of gestation showed a negative correlation to the percentage of resorptions $(p=0.0004$, Rho $=-0.806)$ and the percentage of malformations $(p=0.0112$, Rho $=-0.567$, Spearman rank correlation).

Maternal plasma. The concentration of 8-iso-PGF $2 \alpha$ was not significantly different (over-all $p$-val$\mathrm{ue}=0.11$, ANOVA) between any of the experimental groups in maternal plasma but the mean values of diabetic rats tended to be higher than their respective control group (Fig. 2A). In fact, the combined $\mathrm{N}$ and NP groups displayed lower mean plasma 8-iso$\mathrm{PGF}_{2 \alpha}$ concentration $(663 \pm 126, n=24)$ than did the combined D and DP group $(1184 \pm 140, n=40$, 


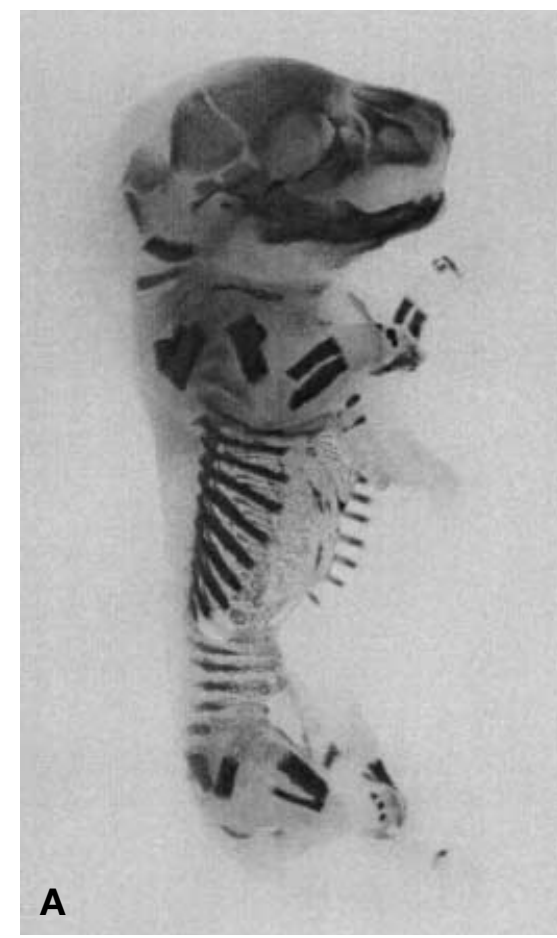

Fig. 1. Alizarin Red stained rat fetuses from gestational day 19. To the left (A) a normal fetus of a non-diabetic rat. To the right (B) a fetus of a diabetic rat displaying micrognathia

$p<0.01$, Students $t$ test). In maternal plasma, the concentration of $15-\mathrm{K}-\mathrm{DH}-\mathrm{PGF}_{2 \alpha}$ was higher in both pregnant (NP and DP) groups compared to their non-pregnant counterparts (N and D) (Fig. 2B). Diabetes induced no difference in plasma $15-\mathrm{K}-\mathrm{DH}-$ $\mathrm{PGF}_{2 \alpha}$ concentration (Fig. 2B).

Maternal plasma glucose concentrations at the end of the experiment did not differ between $\mathrm{N}$ and $\mathrm{NP}$ rats. The $\mathrm{D}$ rats displayed somewhat lower plasma glucose concentration than the DP rats, and both diabetic groups showed a glucose concentration of about four times higher than their non-diabetic counter-

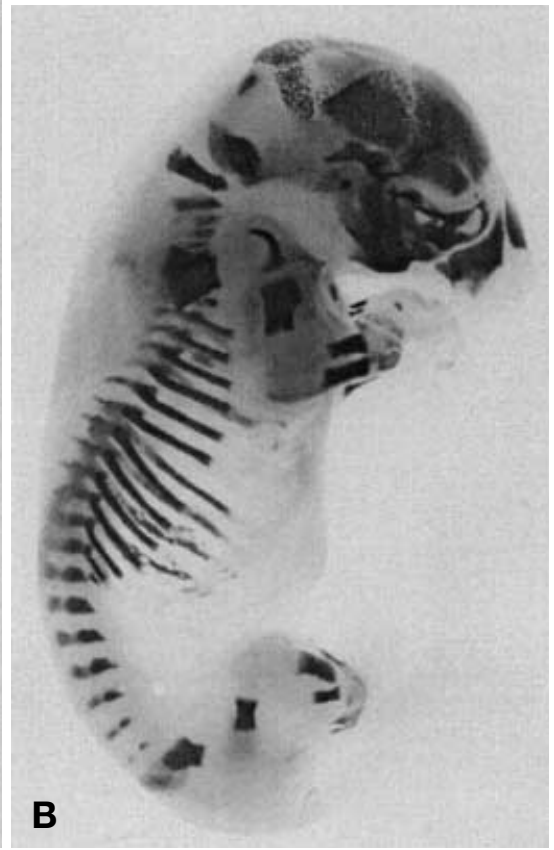

parts (Table 2). The concentrations of cholesterol were higher in the plasma of DP rats than in NP rats, whereas no difference was detected between $\mathrm{N}$ and $\mathrm{D}$ rats (Table 2). The triglyceride concentrations were lower in the non-pregnant than in the pregnant groups; the NP rats had lower concentrations than the DP rats. No difference was seen between the non-pregnant groups. The concentration of $\alpha$-tocopherol was lower in the non-pregnant than in the pregnant rats. However, the lipid (cholesterol + triglycerides) corrected concentration of $\alpha$-tocopherol was decreased by pregnancy (Table 2). Furthermore, the lipid corrected $\alpha$-tocopherol concentration was lower in the $\mathrm{D}$ rats than in the $\mathrm{N}$ rats and tended $(p=0.06)$ to be lower in the DP than in the NP group (Table 2). The ascorbate concentration was not affected by pregnancy, however D rats showed lower concentrations compared with $\mathrm{N}$ rats and a similar

Table 2. Maternal data at gestational day 19

\begin{tabular}{lcccc}
\hline & $\mathrm{N}$ & $\mathrm{NP}$ & $\mathrm{D}$ & $\mathrm{DP}$ \\
\hline Maternal weight end of experiment $(\mathrm{g})$ & $280 \pm 7$ & $380 \pm 6^{\mathrm{a}}$ & $240 \pm 4^{\mathrm{b}}$ & $312 \pm 11^{\mathrm{a}, \mathrm{b}}$ \\
Plasma-glucose (mmol/l) & $7.2 \pm 0.3$ & $5.7 \pm 0.2$ & $27.9 \pm 1.4^{\mathrm{b}}$ & $33.9 \pm 0.9^{\mathrm{a}, \mathrm{b}}$ \\
Cholesterol (mmol/l) & $1.8 \pm 0.05$ & $1.8 \pm 0.1$ & $2.2 \pm 0.2$ & $2.5 \pm 0.1^{\mathrm{a}, \mathrm{b}}$ \\
Triglycerides (mmol/l) & $0.6 \pm 0.08$ & $4.6 \pm 0.8^{\mathrm{a}}$ & $2.2 \pm 0.6$ & $7.4 \pm 0.7^{\mathrm{a}, \mathrm{b}}$ \\
$\alpha$-tocopherol (mmol/l) & $7.0 \pm 0.2$ & $10.3 \pm 0.4^{\mathrm{a}}$ & $7.5 \pm 0.8$ & $10.8 \pm 0.7^{\mathrm{a}}$ \\
$\alpha$-tocopherol/lipid & $2.9 \pm 0.1$ & $1.6 \pm 0.2^{\mathrm{a}}$ & $2.2 \pm 0.3^{\mathrm{b}}$ & $5.6 \pm 0.6^{\mathrm{b}}$ \\
Ascorbate (mg/l) & $10.4 \pm 1.0$ & $8.8 \pm 2.0$ & $3.3 \pm 0.8$ & $4.8 \pm 0.86^{\mathrm{a}}$ \\
Plasma TBARS (mmol/l) & $2.0 \pm 0.5$ & $3.3 \pm 0.7$ & $5.3 \pm 0.7$ & $29.8 \pm 4.6$ \\
Liver TBARS (nmol/g) & $34.5 \pm 1.4$ & $27.3 \pm 2.7$ & $25.4 \pm 1.7$ \\
\hline
\end{tabular}

$\mathrm{N}=$ normal non-pregnant rats, $\mathrm{NP}=$ normal pregnant rats, $\mathrm{D}=$ diabetic non-pregnant rats and $\mathrm{DP}=$ diabetic pregnant rats. Values are given as means \pm SEM. Statistical analysis with ANOVA and Bonferroni/Dunns post-hoc test. ${ }^{\text {a denotes }}$ a significant difference towards respective non-pregnant group, ${ }^{b}$ towards respective non-diabetic control. $n=16(\mathrm{~N}), 8$ (NP), 20 (D), 20 (DP) 

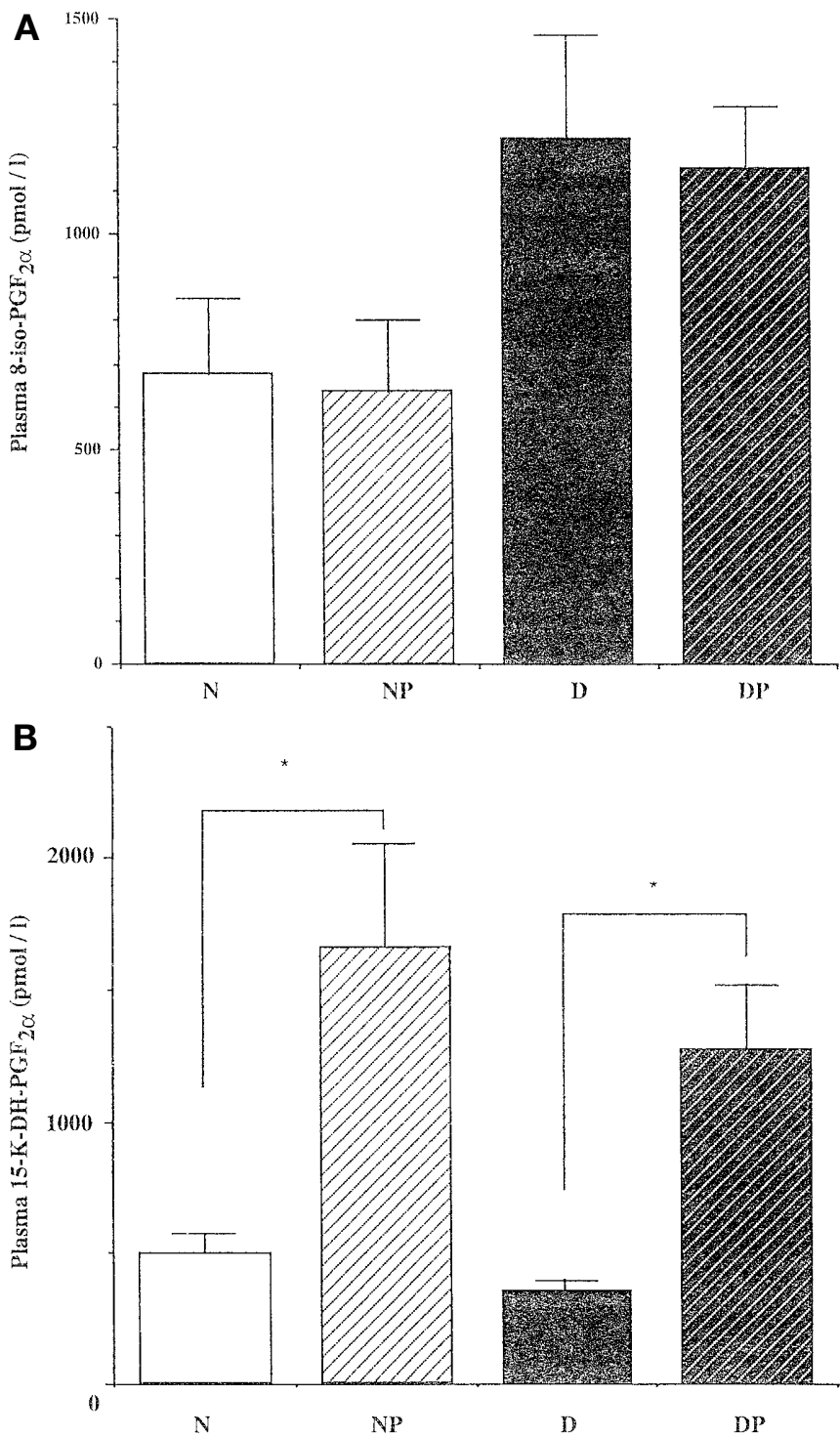

Fig. 2 (A-B) Plasma 8-iso- $\mathrm{PGF}_{2 \alpha}$ concentrations (pmol/l) in female non-pregnant and pregnant normal (N and NP) and diabetic (D and DP) rats. Bars represent means + SEM. $n=16$ (N), 8 (NP), 20 (D), 20 (DP) B Plasma 15-K-DH-PGF ${ }_{2 \alpha}$ concentrations (pmol/l) in female non-pregnant and pregnant normal (N and NP) and diabetic (D and DP) rats. Bars represent means + SEM, * denotes a difference $(p<0.05$, ANOVA $)$ between the indicated groups. $n=16(\mathrm{~N}), 8(\mathrm{NP}), 20(\mathrm{D}), 20(\mathrm{DP})$

tendency was apparent in DP and NP rats $(p=0.06)$ (Table 2). No statistically significant effects were noted in the effect of diabetes and pregnancy on plasma TBARS-concentrations. However, pregnancy tended to increase the plasma TBARS concentration in the diabetic groups compared to their respective controls, in particular the DP group concentration tended to exceed the NP group concentration (Table 2).

The plasma content of carbonylated proteins in the non-diabetic rats was about half of that of the carbonyl content in the diabetic counterparts (Fig 3). Pregnancy did not affect the carbonyl content in either normal or diabetic rats (Fig.3).

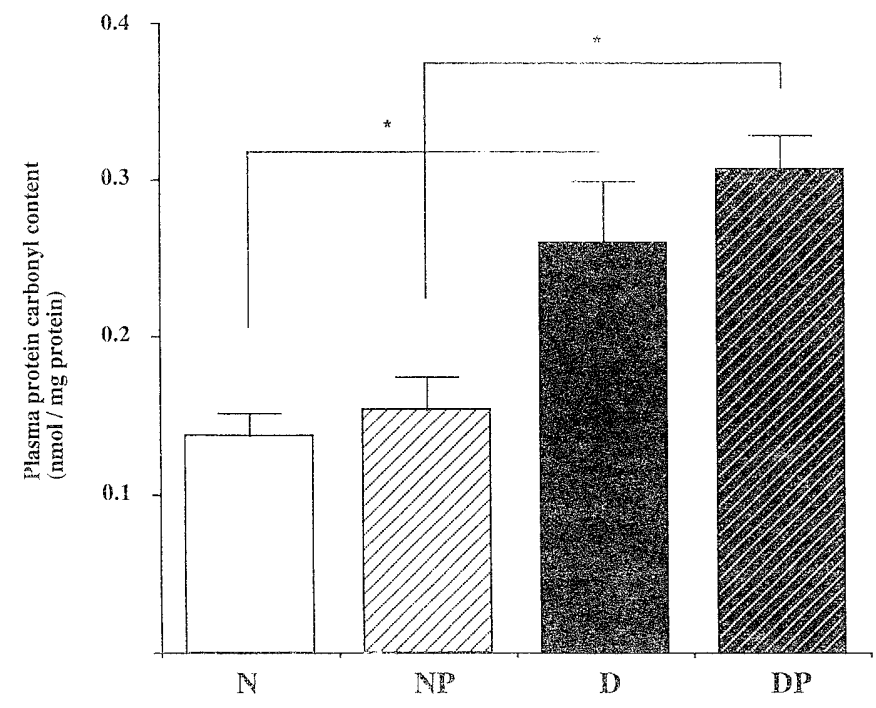

Fig.3. Maternal plasma protein carbonyl concentrations (nmol/mg protein) in female non-pregnant and pregnant normal (N and NP) and diabetic (D and DP) rats. Bars represent means + SEM. $n=16(\mathrm{~N}), 8(\mathrm{NP}), 20(\mathrm{D}), 20(\mathrm{DP})$

Maternal liver. There were no differences in the concentration of TBARS in maternal livers between the groups (Table 2). Maternal liver to body weight ratio was lower in the normal rats compared to their diabetic counterparts (data not shown).

Maternal urine. The creatinine-corrected concentrations of 8-iso- $\mathrm{PGF}_{2 \alpha}$ in urine did not show any difference between the $\mathrm{N}$ and $\mathrm{D}$ rats (Fig. 4A). However, pregnancy caused higher concentrations in the maternal diabetic group (DP vs D) but not in the normal (NP vs N) group (Fig. 4A). The values for accumulated $24 \mathrm{~h}$ urinary excretion of 8 -iso- $\mathrm{PGF}_{2 \alpha}$ showed largely the same pattern as the creatinine corrected concentrations with the exception that the $\mathrm{N}$ group showed a lower 8-iso- $\mathrm{PGF}_{2 \alpha}$ content than the D group (Fig. 4B).

Fetal liver. The fetal liver concentration of TBARS was markedly higher in offspring of diabetic rats than in offspring of normal rats (Fig.5). The mean content of carbonylated proteins in fetal livers was higher in offspring of diabetic rats than in normal offspring (Fig. 5). The morphology of the offspring did not affect the TBARS or protein carbonyl content of the fetal livers (data not shown).

Amniotic Fluid. No difference was found between the normal and diabetic groups in the concentration of either 8-iso- $\mathrm{PGF}_{2 \alpha}$ or $15-\mathrm{K}-\mathrm{DH}-\mathrm{PGF}_{2 \alpha}$ in amniotic fluid of fetuses with normal morphology ('NPO' compared with 'DPO normal' Fig. 6A and B). In the diabetic group the amniotic fluid concentration of 8-iso$\mathrm{PGF}_{2 \alpha}$, tended to be higher in fluid of resorbed fetuses (Fig. 6A) but failed to reach statistical significance 

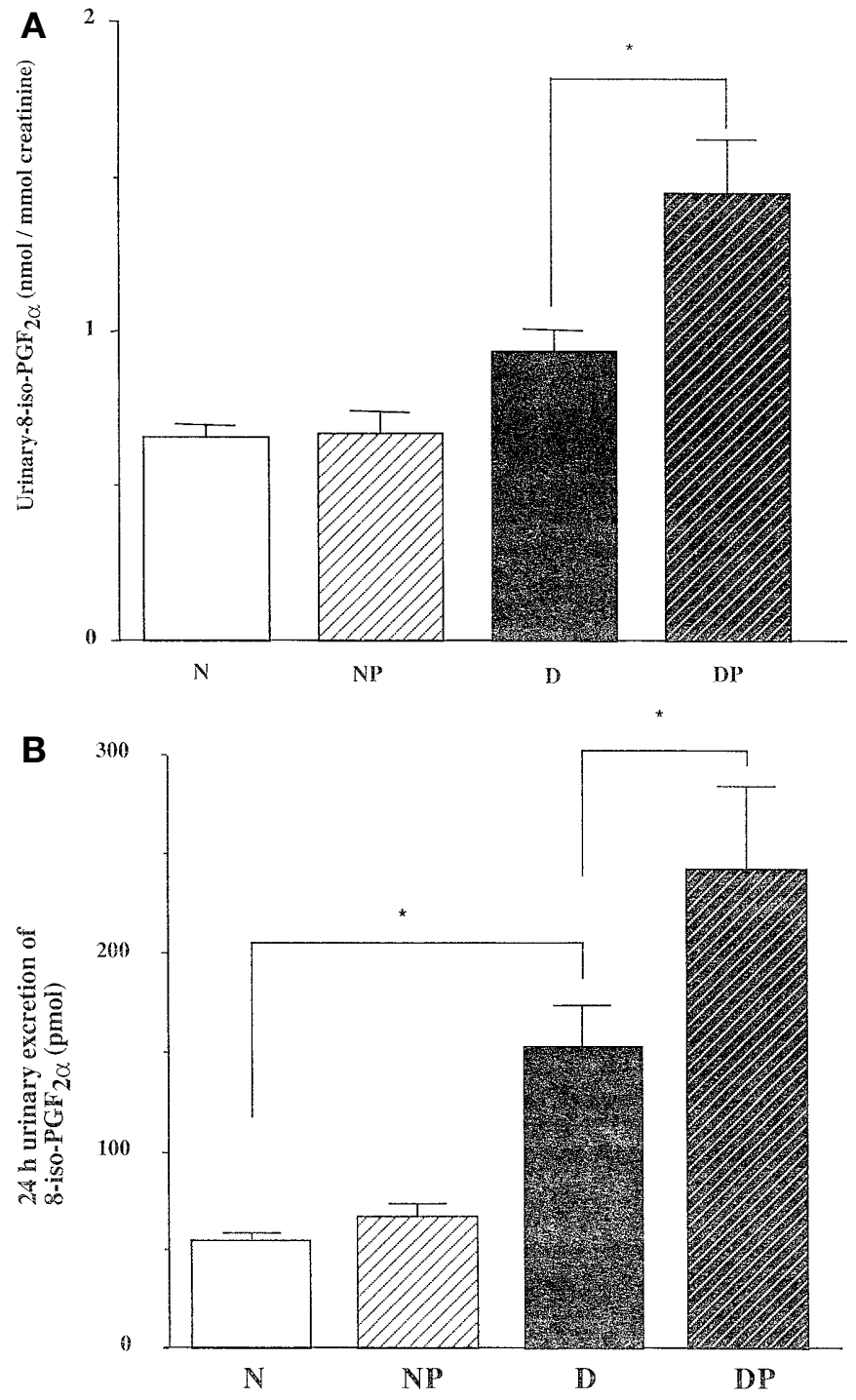

Fig.4. (A-B) A Urinary concentration of 8-iso-PGF ${ }_{2 \alpha}(\mathrm{nmol} /$ mmol creatinine) in female non-pregnant and pregnant normal ( $\mathrm{N}$ and NP) and diabetic (D and DP) rats. Bars represent means \pm SEM. * denotes a difference between indicated groups $(p<0.05$, ANOVA). $n=16(\mathrm{~N}), 8(\mathrm{NP}), 20(\mathrm{D}), 20$ (DP) B Total $24 \mathrm{~h}$ urinary excretion of 8-iso- $\mathrm{PGF}_{2 \alpha}(\mathrm{pmol})$ in female non-pregnant and pregnant normal (N and NP) and diabetic (D and DP) rats. Bars represent means + SEM. * denotes a difference between indicated groups $(p<0.05$, ANOVA). $n=16(\mathrm{~N}), 8(\mathrm{NP}), 20(\mathrm{D}), 20$ (DP)

( $p=0.096$, Kruskall-Wallis test). The concentration of 8 -iso-PGF ${ }_{2 \alpha}$ in amniotic fluid from malformed fetuses was equal to that in normal fetuses (Fig. 6A). The concentration of $15-\mathrm{K}-\mathrm{DH}-\mathrm{PGF}_{2 \alpha}$ was lower in amniotic fluid from malformed fetuses than in fluid from normal fetuses ("DPO malformed" compared with "DPO normal", Fig.6B). The concentration of $15-\mathrm{K}-\mathrm{DH}-\mathrm{PGF}_{2 \alpha}$ in amniotic fluid of resorbed fetuses (DPO resorbed) was not different $(p=0.15)$ from that of normal fetuses (DPO normal) although the mean was numerically higher (Fig.6B).

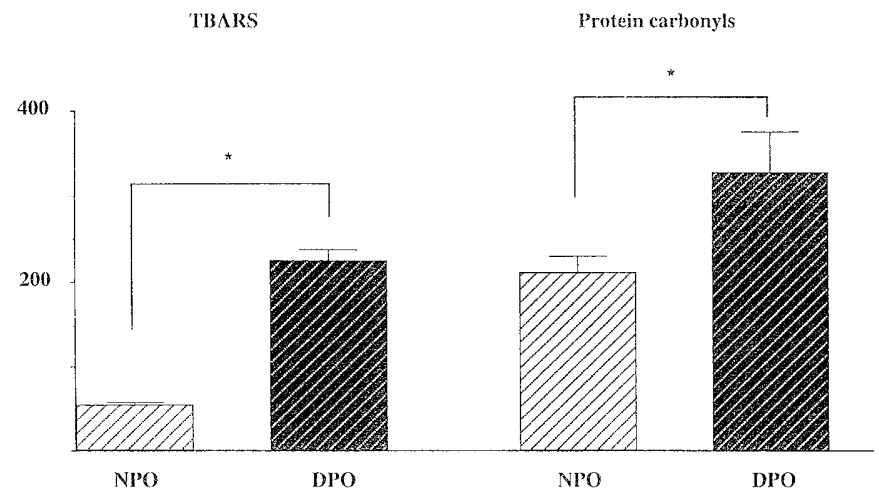

Fig. 5. Concentration in fetal livers of TBARS (nmol/g) and protein carbonyls (pmol/mg protein). NPO and DPO denote livers from offspring of normal mothers and diabetic mothers, respectively. Values are given as means + SEM. * denotes $p<0.05$ between the indicated groups (Mann-Whitney Utest). $n=8$ (NPO), 27 (DPO)

Table 3. Amniotic fluid values in normal and diabetic pregnancy

\begin{tabular}{lll}
\hline & $\begin{array}{l}\text { Normal } \\
\text { pregnancy }\end{array}$ & $\begin{array}{l}\text { Diabetic } \\
\text { pregnancy }\end{array}$ \\
\hline $\begin{array}{l}\text { Amniotic concentration of 8-iso-PGF } \\
\text { correlation to \% malformations }\end{array}$ & - & N. S. \\
$\begin{array}{l}\text { Amniotic concentration of 15-K-DH- } \\
\text { PGF }_{2 \alpha} \text { correlation to \% malformations }\end{array}$ & - & N. S. \\
$\begin{array}{l}\text { Amniotic concentration of 8-iso-PGF } 2 \alpha \\
\text { correlation to \% resorptions }\end{array}$ & N.S. & $p=0.043$ \\
$\begin{array}{l}\text { Amniotic concentration of 15-K-DH- } \\
\text { PGF }_{2 \alpha} \text { correlation to \% resorptions }\end{array}$ & $p=0.049$ & $p=0.0065$ \\
\hline
\end{tabular}

Values are given as means \pm SEM. Statistical analyses with Spearmans rank correlation. Individual $p$-values denote significant $(p<0.05)$ rank correlations

The uterine horn-mean amniotic fluid concentration of 8-iso- $\mathrm{PGF}_{2 \alpha}$ correlated with the rate of resorptions in that horn in the diabetic group (Table 3). The mean amniotic fluid concentration of $15-\mathrm{K}-\mathrm{DH}-$ $\mathrm{PGF}_{2 \alpha}$ correlated with the rate of resorptions in both control and diabetic pregnancies (Table 3).

\section{Discussion}

Diabetic pregnancy yielded increased rates of lipid peroxidation and protein carbonylation both in the mother and in the fetus. Measurement of isoprostane content in $24 \mathrm{~h}$ urine samples could provide a useful estimate of lipid peroxidation rate, an estimate superior to plasma determination of isoprostanes or TBARS.

Fetal weights were decreased and rates of resorptions and malformations increased in diabetic rat pregnancy; this correlates with previous studies in rodent models of diabetic pregnancy [33, 34]. These 

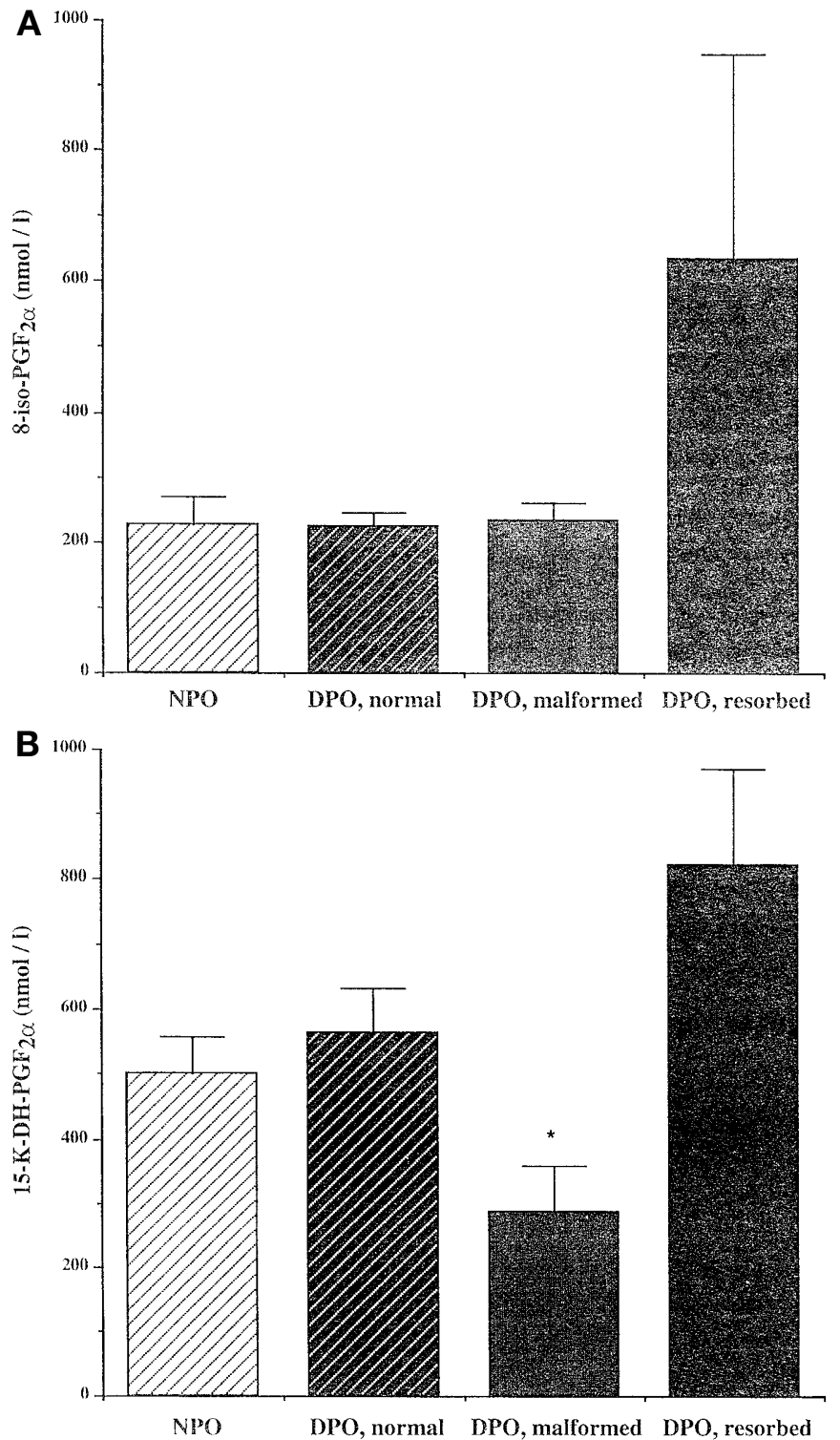

Fig. 6. (A, B) Concentration of (A) 8-iso-PGF ${ }_{2 \alpha}(\mathrm{pmol} / \mathrm{l})$ and (B) $15-\mathrm{K}-\mathrm{DH}-\mathrm{PGF}_{2 \alpha}(\mathrm{pmol} / \mathrm{l})$. NPO denotes amniotic fluid of offspring from normal mothers, and DPO denotes amniotic fluid of offspring from diabetic mothers. The latter group is subdivided with respect to the morphology of the fetus. Values are given + SEM. * denotes a difference versus the DPO, normal group. Kruskall-Wallis test was performed for over-all test of significance and Mann-Whitneys U-test for pairwise comparisons

negative outcomes are most likely to be caused by oxidative stress since the general morphological outcome is ameliorated by antioxidant therapy $[10,12$, $35,36]$. In the diabetic group, the rate of resorbed and malformed fetuses per litter correlated negatively with maternal weight. Since a hampered weight gain could signify a state of severe diabetes-induced effects on maternal metabolism, this finding might indicate that pregnant animals with severe diabetes are prone to have affected offspring. This could be due to common genetic factors in the mother and offspring or to a metabolically more severe environment affecting the fetus. The fewer implantations per litter in the diabetic group could be due to a very early, negative effect of maternal diabetes impairing the process of implantation or to very early resorptions no longer visible on gestational day 19.

The plasma concentrations of 8-iso $\mathrm{PGF}_{2 \alpha}$ did not show any statistically significant differences between the groups in this study. However, the isoprostane concentrations tended to be higher in both diabetic groups compared with controls. The mean concentration was higher in the combined diabetic group compared with the combined control group. In addition, we found increased urinary amounts of 8-iso $\mathrm{PGF}_{2 \alpha}$ in the diabetic pregnant group compared to the nondiabetic pregnant group, both measured as concentration/creatinine and as total $24 \mathrm{~h}$ urinary excretion.

The isoprostanes are formed in place on phospholipids from which they are released into the circulation, most likely by phospholipases [37]. The isoprostanes are then rapidly excreted into the urine; the plasma $\mathrm{t}_{1 / 2}$ of 8 -iso $\mathrm{PGF}_{2 \alpha}$ in the rabbit has been estimated to be a few minutes [38]. Urinary measurements of isoprostanes are more likely to give an integrated view of isoprostane production just before and during the time the sample is collected, in this case 24 hours. Urinary measurements might therefore compensate for the variations in isoprostane concentration over a certain period of time, variations which possibly contribute to the large spread in the plasma measurements. Therefore, frequent samples need to be collected to assess the integrated 8iso $\mathrm{PGF}_{2 \alpha}$ concentration in plasma $[26,27]$. We therefore assume that the urinary isoprostane values can disclose more about the lipid peroxidation process over a period of time than do the plasma values.

The oxidative stress, measured as $24 \mathrm{~h}$ urinary excretion of 8-iso $\mathrm{PGF}_{2 \alpha}$, is more marked in the diabetic rat than in the normal rat and this difference is further increased in pregnancy, indicating that pregnancy during diabetes causes a propensity to lipid peroxidation. The pattern of plasma TBARS concentrations further strengthens this notion. A similar phenomenon has been reported of an increase in lipid peroxidation in plasma of pregnant rats fed a diet high in saturated fat but no such increase was described in non-pregnant rats regardless of diet [39]. The pregnant state in itself, can therefore potentiate diabetes-induced lipid peroxidation.

Protein carbonyl content in plasma was increased by experimental diabetes but not changed by pregnancy. Biochemically modified proteins have been suggested to be a sign of tissue damage caused by oxidative stress, carbohydrate overload or both [40]. The concentrations per mg protein in our study were in the same range as those found in human plasma by other investigators [41]. Isoprostane concentrations vary rapidly due to their short half-life whereas 
proteins, and protein carbonyls, are more stable. The protein carbonyl content therefore possibly reflects the amount of oxidative stress the animal has been exposed to during a longer time period, whereas lipid peroxidation measured as isoprostane concentration gives a measure of the acute oxidative status.

The decreased plasma $\alpha$-tocopherol concentrations (lipid-corrected) in pregnant rats compared with those in non-pregnant rats indicate that the lipid-phase antioxidant defense is impaired during pregnancy. Furthermore, the maternal plasma ascorbate concentrations were changed by pregnancy, but decreased by diabetes. The resulting effect is decreased maternal antioxidative capacity in diabetic pregnancy compared to non-diabetic pregnancy.

The amniotic concentrations of 8-iso-PGF ${ }_{2 \alpha}$ and of $15-\mathrm{K}-\mathrm{DH}-\mathrm{PGF}_{2 \alpha}$ were similar in fetuses with normal morphology from non-diabetic and diabetic rats. Both the isoprostane and the prostaglandin metabolite concentration tended to be higher in amniotic fluid from resorbed fetuses. The concentration of $15-\mathrm{K}-$ DH-PGF ${ }_{2 \alpha}$ was lower in amniotic fluid of malformed fetuses. This could be due to an underproduction of prostaglandins, as it has been associated with embryos of diabetic rats [28]. Furthermore, amniotic concentration of 8-iso-PGF ${ }_{2 \alpha}$ and 15-K-DH-PGF ${ }_{2 \alpha}$ in a given uterine horn correlated positively with the percentage of resorptions in that horn. These findings indicate increased lipid peroxidation and enhanced inflammatory processes in resorbed fetuses. Because these are late-gestational measurements it could be assumed that these processes are induced by the resorption process rather than causing it.

In the fetal livers, the concentration of TBARS and of carbonylated proteins were higher in offspring of diabetic rats than in offspring of non-diabetic rats. This indicates that the fetuses, as well as their mothers, are subjected to oxidative stress affecting both lipid and protein compartments. In the diabetic group, there was no difference in TBARS or carbonylated protein concentrations between offspring with normal morphology and offspring displaying micrognathia. This indicates that livers of malformed fetuses are not, in late gestation, subjected to more oxidative protein or lipid damage than the livers of non-malformed fetuses. Thus, increase in lipid and protein oxidative damage in a fetal liver does not seem to be a sign of malformed fetus. Causative relations, if they exist, would more likely be found earlier in pregnancy.

In conclusion, we have shown that experimental diabetic pregnancy is a condition with increased lipid peroxidation, not only compared to normal pregnant rats but also to non-pregnant diabetic rats. Maternal diabetes increases protein carbonylation and lipid peroxidation rates both in maternal and fetal tissues. No clear-cut correlation between fetal morphology and fetal or amniotic fluid oxidative stress markers were found. However, isoprostane concentrations in amniotic sacs of resorbed offspring tend to be increased compared to normal offspring, suggesting a potential use in predicting embryo maldevelopment.

Acknowledgements. The expert technical assistance of L. Sagulin, E. Sejby and B. Simu is greatly acknowledged. This study was supported by The Ernfors Family Fund, The Swedish Diabetes Association, The Söderberg Foundation, The Novo Nordisk Foundation and The Swedish Medical Research Council (Grant No. 12X-7475 and 12X-109).

\section{References}

1. Suhonen L, Hiilesmaa V, Teramo K (2000) Glycaemic control during early pregnancy and fetal malformations in women with type I diabetes mellitus. Diabetologia 43: $79-82$

2. Greene MF (1999) Spontaneous abortions and major malformations in women with diabetes mellitus. Semin Reprod Endocrinol 17: 127-136

3. Mills JL, Baker L, Goldman AS (1979) Malformations in infants of diabetic mothers occur before the seventh gestational week. Implications for treatment. Diabetes 28: 292-293

4. Eriksson RSM, Thunberg L, Eriksson UJ (1989) Effects of interrupted insulin treatment on fetal outcome of pregnant diabetic rats. Diabetes 38: 764-772

5. Leslie RDG, Pyke DA, John PN, White JM (1978) Hemoglobin A1 in diabetic pregnancy. Lancet II: 958-959

6. Greene MF, Hare JW, Cloherty JP, Benacerraf BR, Soeldner JS (1989) First-trimester hemoglobin $\mathrm{A}_{1}$ and risk for major malformation and spontaneous abortion in diabetic pregnancy. Teratology 39: 225-231

7. Hanson U, Persson B, Thunell S (1990) Relationship between haemoglobin A1 c in early type 1 (insulin-dependent) diabetic pregnancy and the occurrence of spontaneous abortion and fetal malformation in Sweden. Diabetologia 33: 100-104

8. Eriksson UJ, Borg LAH (1991) Protection by free oxygen radical scavenging enzymes against glucose-induced embryonic malformations in vitro. Diabetologia 34: 325-331

9. Eriksson UJ, Borg LA (1993) Diabetes and embryonic malformations. Role of substrate-induced free-oxygen radical production for dysmorphogenesis in cultured rat embryos. Diabetes 42: 411-419

10. Viana M, Herrera E, Bonet B (1996) Teratogenic effects of diabetes mellitus in the rat. Prevention with vitamin E. Diabetologia 39: 1041-1046

11. Eriksson UJ, Simán CM (1996) Pregnant diabetic rats fed the antioxidant butylated hydroxytoluene show decreased occurrence of malformations in the offspring. Diabetes 45: 1497-1502

12. Simán CM, Eriksson UJ (1997) Vitamin E decreases the occurence of malformations in the offspring of diabetic rats. Diabetes 46: 1054-1061

13. Simán CM, Eriksson UJ (1997) Malformations in the offspring of diabetic rats are prevented by supplementation of the maternal diet with vitamin C. Diabetologia 40: 1416-1424

14. Reece EA, Wu Y-K (1997) Prevention of diabetic embryopathy in offspring of diabetic rats with use of a cocktail of deficient substrates and an antioxidant. Obstet Gynecol 176: 790-798 
15. Winitzer A, Ayalon N, Hershkovitz R et al. (1999) Lipoic acid prevention of neural tube defects in offspring of rats with streptozocin-induced diabetes. Am J Obstet Gynecol 180: 188-193

16. Morrow JD, Harris TM, Roberts LJI (1990) Noncyclooxygenase oxidative formation of a series of novel prostaglandins: analytical ramifications for measurement of eicosanoids. Anal Biochem 184: 1-10

17. Morrow JD, Minton TA, Badr KF, Roberts LJI (1994) Evidence that the $\mathrm{F}_{2}$-isoprostane, 8-epi-prostaglandin $\mathrm{F}_{2 \alpha}$, is formed in vivo. Biochim Biophys Acta 1210: 244-248

18. Takahashi K, Nammour TM, Fukunaga M et al. (1992) Glomerular actions of a free radical-generated novel prostaglandin, 8-epi-prostaglandin $\mathrm{F}_{2}$ in the rat. J Clin Invest 90: 136-141

19. Michoud E, Lecomte M, Lagarde M, Wiernsperger N (1998) In vivo effect of 8-iso-PGF2 a on retinal circulation in diabetic and non-diabetic rats. Prostaglandins Leukot Essent Fatty Acids 59: 349-355

20. Gerber RT, Holemans K, O'Brien-Coker I et al. (2000) Increase of the isoprostane 8-isoprostaglandin F2alpha in maternal and fetal blood of rats with streptozotocin-induced diabetes: evidence of lipid peroxidation. Am J Obstet Gynecol 183: 1035-1040

21. Davies KJ, Delsignore ME, Lin SW (1987) Protein damage and degradation by oxygen radicals. II. Modification of amino acids. J Biol Chem 262: 9902-9907

22. Miyata T, Inagi R, Asahi K et al. (1998) Generation of protein carbonyls by glycoxidation and lipoxidation reactions with autoxidation products of ascorbic acid and polyunsaturated fatty acids. FEBS Lett 437: 24-28

23. Odetti P, Garibaldi S, Noberasco G et al. (1999) Levels of carbonyl groups in plasma proteins of type 2 diabetes mellitus subjects. Acta Diabetol 36: 179-183

24. Samuelsson B, Goldyne M, Granstrom E, Hamberg M, Hammarstrom S, Malmsten C (1978) Prostaglandins and thromboxanes. Annu Rev Biochem 47: 997-1029

25. Basu S, Kindahl H, Harvey D, Betteridge KJ (1987) Metabolites of PGF2 alpha in blood plasma and urine as parameters of PGF2 alpha release in cattle. Acta Vet Scand 28: 409-420

26. Basu S, Eriksson M (1998) Oxidative injury and survival during endotoxemia. FEBS Lett 438: 159-160

27. Basu S, Eriksson M (2000) Lipid peroxidation induced by an early inflammatory response in endotoxaemia. Acta Anaesthesiol Scand 44: 17-23

28. Wentzel P, Welsh N, Eriksson UJ (1999) Developmental damage, increased lipid peroxidation, diminished cyclooxy- genase-2 gene expression, and lowered PGE2 levels in rat embryos exposed to a diabetic environment. Diabetes 48: 813-820

29. Basu S (1998) Radioimmunoassay of 8-iso-prostaglandin $\mathrm{F}_{2 \alpha}$ : an index for oxidative injury via free radical catalysed lipid peroxidation. Prostaglandins Leukot Essent Fatty Acids 58: 319-325

30. Basu S (1998) Radioimmunoassay of 15-keto-13, 14-dihydro-prostaglandin $\mathrm{F}_{2 \alpha}$ : an index for inflammation via cyclooxygenase catalysed lipid peroxidation. Prostaglandins Leukot Essent Fatty Acids 58: 347-352

31. Ohrvall M, Tengblad S, Vessby B (1993) Lower tocopherol serum levels in subjects with abdominal adiposity. J Intern Med 234: 53-60

32. Jagota SK, Dani HM (1982) A new colorimetric technique for the estimation of vitamin $\mathrm{C}$ using Folin phenol reagent. Anal Biochem 127: 178-182

33. Lazarow A, Kim JN, Wells LJ (1960) Birth weight and fetal mortality in pregnant subdiabetic rats. Diabetes 9: 114-117

34. Eriksson UJ, Dahlström E, Larsson KS, Hellerström C (1982) Increased incidence of congenital malformation in the offspring of diabetic rats and their prevention by maternal insulin therapy. Diabetes 31: 1-6

35. Sivan E, Reece EA, Wu YK, Homko CJ, Polansky M, Borenstein M (1996) Dietary vitamin E prophylaxis and diabetic embryopathy: morphologic and biochemical analysis. Am J Obstet Gynecol 175: 793-799

36. Cederberg J, Siman CM, Eriksson UJ (2000) Combined treatment with vitamin $\mathrm{E}$ and vitamin $\mathrm{C}$ decreases oxidative stress and improves foetal outcome in experimental diabetic pregnancy. Pediatr Res (In Press)

37. Morrow JD, Awad JA, Boss HJ, Blair IA, Roberts LJd (1992) Non-cyclooxygenase-derived prostanoids (F2-isoprostanes) are formed in situ on phospholipids. Proc Natl Acad Sci USA 89: 10721-10725

38. Basu S (1998) Metabolism of 8-iso-prostaglandin $F_{2 \alpha}$. FEBS Lett 428: 32-36

39. Gerber RT, Holemans K, O'Brien-Coker I et al. (1999) Cholesterol-independent endothelial dysfunction in virgin and pregnant rats fed a diet high in saturated fat. J Physiol (Lond) 571: 607-616

40. Baynes JW, Thorpe SR (1999) Role of oxidative stress in diabetic complications. A new perspective on an old paradigm. Diabetes 48: 1-9

41. Buss H, Chan TP, Sluis KB, Domigan NM, Winterbourn CC (1997) Protein carbonyl measurement by a sensitive ELISA method. Free Radic Biol Med 23: 361-366 